\title{
Composite indicators as generalized benefit-of-the-doubt weighted averages
}

\author{
Nicky Rogge \\ KU Leuven, Faculty of Economics and Business, Onderzoekseenheid ECON-CEDON Warmoesberg 26, 1000 Brussels, Belgium
}

\section{A R T I C L E I N F O}

\section{Article history:}

Received 16 December 2016

Accepted 22 November 2017

Available online $\mathrm{xxx}$

\section{Keywords:}

Data Envelopment Analysis

Benefit-of-the-doubt model

Composite indicator

Generalized mean aggregation

Human Development Index

\begin{abstract}
A B S T R A C T
Composite indicators (CIs) are usually computed as arithmetic (weighted) averages of (often normalized) sub-indicators. Several studies criticized this procedure for implying requirements and properties that are often hard to maintain in practical applications. Recent studies explored the multiplicative aggregation and more specifically the geometric (weighted) average as aggregator in CI-building. This paper takes this exploration one step further by considering other members of the family of generalized (weighted) averages as aggregator in the construction of CIs. It is argued that the choice for a particular version of the generalized weighted average enables to reflect decision makers' attitudes in the evaluation. For the Human Development Index, results show that the choice for a specific version of the generalized (weighted) average as aggregator in $\mathrm{CI}$-construction impacts country rankings.
\end{abstract}

(C) 2017 Elsevier B.V. All rights reserved.

\section{Introduction}

Composite Indicators (CIs hereafter), such as the UNDP's wellknown Human Development Index (HDI), have attracted increased attention over the last years, as can be witnessed by the growing literature applying CIs to many different policy-relevant themes. Nevertheless, despite their increasing use, CIs remain controversial and open to criticism (Booysen, 2002; Ravallion, 2012; Sagar \& Najam, 1998). Two particular concerns pertain to the importance weight one should attach to a sub-indicator in terms of its contribution to the final composite construct and the functional form of the aggregator function that is used to aggregate the sub-indicators containing numerical information on theme-relevant dimensions (see, Chakravarty, 2003; Chowdhury \& Squire, 2006)..$^{1}$ The majority of the studies addressed the methodological issue of the weighting of the sub-indicators, i.e., the question on what are proper weights to aggregate the sub-indicators. However, recently, the methodological aspect of aggregating the sub-indicators has gained interest among scholars. Specifically, whereas the arithmetic aggregation, and in particular the use of arithmetic weighted averages of (often normalized) sub-indicators $y_{c, i}^{n}(i=1, \ldots, m)$ (the superscript ' $n$ ' indicates normalized data), i.e., $C I_{c}=\sum_{i=1}^{m} \omega_{i} y_{c, i}^{n}$, has been (and still is) widely used in the construction of CIs in the litera-

E-mail address: nicky.rogge@kuleuven.be

1 Other recurring concerns are, amongst others, the selection of specific subindicators, the fact that these sub-indicators may have different measurement units in their original form and the robustness of the obtained $\mathrm{CI}$-scores and ranks to the modelling options, etc. (for a more elaborate discussion, see Nardo et al., 2008). ture, recent studies explored other functional forms of the aggregation procedure in the construction of CIs. Particularly the multiplicative aggregation and more specifically the use of the geometric weighted average $C I_{c}=\prod_{i=1}^{m}\left(y_{c, i}^{n}\right)^{\omega_{i}}$ has been advocated by many scholars as superior over the more commonly used arithmetic weighted average (Ebert \& Welsh, 2004; Van Puyenbroeck \& Rogge, 2017; Zhou, Ang, \& Zhou, 2010) for several reasons. First, Ebert and Welsch (2004) demonstrated that, if sub-indicators are measured on a ratio-scale and are strictly positive, a weighted geometric average is meaningful in the sense that, when it is applied to different countries, their resulting ordering is independent of the exact scaling of each of the sub-indicators. This is an obvious (and in fact quite compelling) advantage, as otherwise it could be that the ordering of two countries in terms of a composite comparison could switch if one of the constituent sub-indicators is measured in, say, dollars instead of euros, etc. Such invariance results are far more limited in the case of a linear weighted average, implying that there is a greater risk with the latter aggregator that the final ordering is dependent on the original measurement units or the specific normalization method used. Second, geometric aggregation provides one way to deal with the concern that using a linear weighted average as the functional form of a $\mathrm{CI}$ implies perfect substitutability/constant trade-offs between the different subindicators. Or, relatedly, it ensures that the marginal returns to an increase in a sub-indicator value are diminishing rather than constant. Finally, a weighted geometric average penalizes inequality among (normalized) sub-indicators for a country, i.e. results in a lower value for the $\mathrm{CI}$, relative to when a linear aggregator would be used for the same data. The 2010 change in the construction 
of UNDP's Human Development Index (using a geometric average instead of arithmetic average) is a well-known illustration of the increasing popularity of using the geometric weighted average in CI-building (UNDP, 2010; but see Ravallion (2012) for a more nuanced view). ${ }^{2}$

The present paper takes the exploration for functional forms of the aggregation procedure a step further by considering other versions of the generalized (weighted) average as aggregator in the construction of CIs. Whereas the use of generalized weighted average aggregation in CI-building has already been discussed by some previous studies (Decancq \& Lugo, 2013; Guh, Po, \& Lee, 2008; Permanyer, 2012), only few studies explicitly explored the role of choosing a specific version of the generalized weighted average as aggregator in the construction of the $\mathrm{CI}$ and, more in particularly, how this choice is connected to a DM's attitude (notable exception is Guh et al., 2008). Moreover, the papers that did discuss the generalized weighted average as an aggregator in the construction of Cls typically ignore the issue of defining proper aggregation weights (e.g., Guh et al., 2008). In particular, this paper seeks to forward a $\mathrm{Cl}$ construction method that combines different specific cases of the generalized weighted average aggregation with so-called "benefit of the doubt"-weighting (after Cherchye, Moesen, Rogge, \& Van Puyenbroeck, 2007; Melyn \& Moesen, 1991). In essence, the BoD-weighting method is a data-oriented method for deriving weights that is inspired by Data Envelopment Analysis (DEA) (Charnes, Cooper, \& Rhodes, 1978). The conceptual starting point of the BoD-approach is that, in the absence of detailed knowledge on the correct weights for the sub-indicators, information on the weights can be retrieved from the observed subindicator data themselves. Particularly, the basic idea is to put the country sub-indicator data in a relative perspective by comparing them to each other and derive for each country the set of optimal weights such that the country is evaluated in the best possible way relative to the other countries (i.e., highest CI-score). The increasing popularity of the BoD-approach shows by a rapidly increasing number of applications in various policy contexts as well as by different extensions and variants of the basic model in the literature (e.g., Blancas, Contreras, \& Ramírez-Hurtado, 2013; Van Puyenbroeck \& Rogge, 2017; Zhou, Fan, \& Zhou, 2010). As an example, BoD-based versions of the HDI have been presented in the literature by, amongst others, Blancard and Hoarau (2013), Despotis, 2005a, 2005b), Despotis, Stamati, and Smirlis (2009), Mahlberg and Obersteiner (2001), Mariano, Sobreiro, and do Nascimento Rebelatto (2015), Tofallis (2013), and Anderson, Crawford, and Leicester (2011). Other policy contexts with BoD-applications include measuring sustainable energy development (Zhou, Ang, \& Poh, 2007), environmental performance (Rogge, 2012; Zanella, Camanho, \& Dias, 2015), measuring active ageing (e.g., Amado, São José, \& Santos, 2016).

The present paper argues that a CI-construction method that combines generalized (weighted) averages as aggregation operators in combination with "benefit of the doubt"-weighting has more potential to evaluate policy performance in real decision making situations that are characterized by incomplete and/or imprecise information on the true importance weights of the sub-indicators comprising the $\mathrm{CI}$ as well as the evaluation attitude of the decision maker(s). As to the latter, it is argued that the flexibility in choosing a specific member of the generalized (weighted) averages as aggregator in the construction of CIs can be used to reflect the evaluation attitude of the decision maker.

Throughout, the use of a BoD-based generalized weighted average and, in particular, the role and the impact of using different

\footnotetext{
${ }^{2}$ I refer the interested reader to Van Puyenbroeck and Rogge (2017) for a more detailed discussion of the theoretical background on the superiority of the geometric aggregations and arithmetic aggregations in CI-building.
}

versions of the generalized weighted average as aggregator in the construction of CIs is illustrated using the Human Development Index (HDI), a CI that aims at providing a summary measure of country achievement in three key dimensions of human development: having a long and healthy life, being knowledgeable, and having a decent standard of living. ${ }^{3}$ Country achievement in human development is measured by a $m$-tuple of sub-indicators with $m=4$ : (1) $y_{1}$ : life expectancy at birth (years), (2) $y_{2}$ : expected years of schooling (years), (3) $y_{3}$ : mean years of schooling (years), and (4) $y_{4}$ : gross national income (GNI) per capita converted into purchasing power parity (2011 PPP \$). The sub-indicator $y_{1}$ measures the dimension 'long and healthy life', the two sub-indicators $y_{2}$ and $y_{3}$ cover the dimension 'knowledge', and the sub-indicator $y_{4}$ measures the dimension 'a decent standard of living'.

\section{CIs as generalized (BoD-)weighted averages}

In general, an aggregation operator in the construction of a $\mathrm{Cl}$ is a function that aggregates $(\oplus)$ and weighs the country subindicator values into one summative score. Formally this can be denoted as $C I_{c}=\left(\omega_{c, 1} y_{c, 1}^{n} \oplus \omega_{c, 2} y_{c, 2}^{n} \oplus \ldots \oplus \omega_{c, m} y_{c, m}^{n}\right)$ with $C I_{c}$ the composite indicator value for the evaluated country $c, y_{c, i}^{n} \in \mathbb{R}_{+}^{m}$ the (often normalized) sub-indicator values of the evaluated country $c$ on the sub-indicators $i(i=1, \ldots, m), \omega_{c, i}$ the importance weights for the sub-indicators, with $0 \leq \omega_{c, i} \leq 1$ and $\sum_{i=1}^{m} \omega_{c, i}=1$. The commonly used versions of the generalized weighted average for building CIs are the arithmetic (weighted) average and geometric (weighted) average:

$$
\begin{aligned}
& C I_{c}=\sum_{i=1}^{m} \omega_{c, i}\left(y_{c, i}^{n}\right) \\
& C I_{c}=\prod_{i=1}^{m}\left(y_{c, i}^{n}\right)^{\omega_{c, i}}
\end{aligned}
$$

The arithmetic (equal weighted) version as in (1) was used in the older versions of the HDI. The geometric version as in (2) with weights being equal across dimensions was introduced to compute the HDI in 2010 (UNDP, 2010). One of the main reasons for introducing the geometric average in the HDI was the reduction in the level of substitutability between sub-indicators. As discussed above, the arithmetic average aggregation imposes the strong assumption of perfect substitutability (constant trade-offs) between the different sub-indicators. More technically, marginal rates of substitution (MRS) between the sub-indicators are assumed to be constant and, thus, independent of the country's actual performance levels on the sub-indicators. Basically, this implies that a poor achievement on one of the sub-indicators can be linearly compensated for by strong achievements on the other sub-indicators. Moreover, an arithmetic weighted average does not penalize inequality in country performance values among subindicators for a country. Clearly both these implications are undesirable in the measurement of complex policy phenomena such as human development. Contrary to the arithmetic version, the geometric weighted average does not allow a poor achievement on one of the sub-indicators to be linearly compensated for by a strong achievement on other sub-indicators. This implies that poor

\footnotetext{
3 The reason for focusing on measuring multidimensional human development by means of the HDI in the application instead of another topic such as social inclusion, poverty or health is two-fold. Firstly, there is the large popularity of HDI. Since its introduction in 1990 the HDI has become the most well-known composite index. A second reason is that the HDI is probably the most studied composite index with of particular relevance to the topic of the present paper, the recent debate among scholars on what is a proper way of aggregating the human development dimensions into the HDI (UNDP, 2010; Ravallion, 2012).
} 
relative performance values on any of the sub-indicators is directly reflected in a lower HDI-score, all else equal. Another reason is that the geometric average is more respectful of the intrinsic differences between the HDI-dimensions and, as such, provides a better basis for comparisons in country performances in human development.

The family of generalized weighted averages as aggregation operators in the construction of CIs can be denoted in general formal notation as $C I_{c}=\mathrm{f}\left(y_{c, 1}^{n}, y_{c, 2}^{n}, \ldots, y_{c, m}^{n}, \omega_{c, 1}, \omega_{c, 2}, \ldots, \omega_{c, m}, p\right)$ or, in better known formulation, as:

$C I_{c}=\left(\sum_{i=1}^{m} \omega_{c, i}\left(y_{c, i}^{n}\right)^{p}\right)^{1 / p}$

The generalized weighted average operator as in (3) is a monotonically non-decreasing function with respect to the comprising sub-indicator values. Interesting is the parameter $p$. By varying the parameter $p$, different versions of the generalized weighted average are introduced as aggregation operator in the construction of the CI. As is well-known, for the generalized weighted average aggregator, there is an infinity of weighted averages, with values for $p$ varying from $-\infty$ to $+\infty$. The two extreme cases correspond to the $p$-values of $-\infty$ and $+\infty$. For $p=-\infty$, the generalized weighted average aggregator is $C I_{c}=\min \left\{y_{c, 1}^{n}, \ldots, y_{c, m}^{n}\right\}$, implying that the evaluated country's $C I_{c}$ corresponds to the minimum relative performance value of the evaluated country across the sub-indicators. The other extreme case is for $p=+\infty$ : $C I_{C}=$ $\max \left\{y_{c, 1}^{n}, \ldots, y_{c, m}^{n}\right\}$ (for the formal proof, see proof 1 in Appendix). In this case, the evaluated country's $C I_{c}$ parallels to the maximum relative performance value across the sub-indicators. Note that the commonly used aggregators for building CIs, the arithmetic and geometric weighted average as in (1) and (2), are specific members of the family of generalized weighted averages, respectively for $p=1$ and $p=0$ (more correctly, the geometric version of the generalized weighted average correspond to a p-value approaching 0 in the limit, $\lim _{p \rightarrow 0} \mathrm{f}\left(y_{c, 1}^{n}, y_{c, 2}^{n}, \ldots, y_{c, m}^{n}, \omega_{c, 1}, \omega_{c, 2}, \ldots, \omega_{c, m}, p\right)$, see proof 2 in Appendix for the formal proof). Other basic well-known and commonly used specifications of the generalized weighted average include the harmonic weighted average $(p=-1)$, quadratic weighted average $(p=2)$, and the cubic weighted average $(p=3)$, formally respectively in (4), (5) and (6):

$$
\begin{aligned}
& C I_{c}=\frac{1}{\sum_{i=1}^{m} \omega_{c, i}\left(\frac{1}{y_{c, i}^{n}}\right)} \\
& C I_{c}=\left(\sum_{i=1}^{m} \omega_{c, i}\left(y_{c, i}^{n}\right)^{2}\right)^{1 / 2} \\
& C I_{C}=\left(\sum_{i=1}^{m} \omega_{c, i}\left(y_{c, i}^{n}\right)^{3}\right)^{1 / 3}
\end{aligned}
$$

Note, however, that this list is not exhaustive as for every $-\infty \leq p \leq+\infty$, the generalized weighted average aggregator as in (3) produces a different aggregation operator. In general, setting a lower $p$-value corresponds to imposing a higher penalization for relatively poor performances on one or more sub-indicators. Specifying a higher $p$-value generally implies being more rewarding for relatively strong performances on one or more sub-indicators in the evaluation of the overall country performance. Choosing a more intermediate $p$-value means that relatively weak performance values on some sub-indicators are to a certain degree balanced with relatively strong performance values on other sub-indicators, the degree depending on the actual $p$-value.
In the evaluation of complex and multidimensional country performances, in a sense, one could argue that the choice for a particular $p$-value conveys and emulates the decision maker's attitude (see Guh et al. (2008) for a discussion). When the decision maker or policy maker takes a more strict, rigorous stance in the country performance evaluation, a version of the generalized weighted average can be used that is more directed towards the sub-indicator(s) in which the evaluated country obtains the lowest relative performance value(s). This can be done by setting lower (read negative values for the p-parameter in formula (3)). The more harsh the evaluation attitude of the decision maker or policy maker, in the sense that the focus is more on the sub-indicator(s) in which the countries perform poorly, the more negative the value for the $p$-parameter should be set in order to implement this more harsh evaluation attitude in the construction of the CIs, all else equal. Following this line of reasoning, the most extreme rigorous evaluation attitude corresponds to setting a $p$-value equal to $-\infty$ in which $C I_{c}$ is completely determined by the minimum relative performance value of the evaluated country across the sub-indicators. That is, the evaluation attitude of the decision maker is so extremely stringent that the information on the importance weights of the sub-indicators is ignored in the construction of the $\mathrm{CI}$. The opposite reasoning holds for when the decision maker(s) is (are) more flexible and/or optimistic in the evaluation of the country performances with a focus on the sub-indicators on which the country performs well. This requires setting a positive $p$-value in the generalized weighted average aggregation in the CI-building. The more flexible and optimistic the evaluation attitude of the decision maker or, stated differently, the more that the decision maker focuses on the sub-indicators on which the evaluated countries perform well, the more positive should be the $p$-parameter, all else equal. The most extreme version of this optimistic stance is when the $p$-value equals $+\infty$ and the $C I_{c}$ is determined exclusively by the sub-indicator in which the evaluated country realizes the maximum relative performance value. Or, stated otherwise, by setting the $p$-value equal to $+\infty$, one can emulate an evaluation attitude of the decision maker that is extremely mild in the sense that in the evaluation the focus is solely on the sub-indicator with the highest relative performance value. In sum, the advantage of choosing more positive values for the $p$-parameter, ceteris paribus, is that the sub-indicators on which the countries are doing well, will have a higher impact on the CI-score (with the impact being higher for more positive $p$-values). The disadvantage of setting more positive $p$-values in the construction of the generalized weighted average $\mathrm{CI}$ is that the sub-indicators on which the evaluated countries obtain weaker performances will less influence the overall CI-score, other things equal. By setting a more intermediate $p$-value (i.e., $p$-values around 1), one can implement a more neutral evaluation attitude of the decision maker, i.e., a more balanced appreciation of the relative strengths and weaknesses in the country performances on the sub-indicators. For instance, using a mildly negative (positive) $p$-value (e.g., $p$-value $=-1$ vs. $p$-value $=1$ ) in the specification of the generalized weighted average aggregator in the CI-building corresponds to a setting in which the decision maker has an evaluation attitude that is slightly skewed towards the sub-indicators on which the countries perform weakly (strongly), however, not so skewed as paying almost no attention to the other sub-indicators. ${ }^{4}$

\footnotetext{
${ }^{4}$ Following the reasoning that setting positive (negative) $p$-values results in giving (more) less significance to sub-indicators on which the evaluated country obtains higher (lower) performance values, the $\mathrm{CI}$-score as computed by the harmonic weighted average aggregation ( $p$-value $=-1$ ) relates to the CI-score as computed by the arithmetic weighted average aggregation $(p$-value $=+1)$ as follows: $C I_{c}(p=-1)$ $\leq C I_{c}(p=+1)$.
} 
In practical applications there are multiple reasons for examining the impact of using different versions of the generalized weighted average as aggregator in the $\mathrm{Cl}$-computations. Firstly, as discussed above, the choice for a particular $p$-value is in essence normative as it emulates policy values or judgments of policy makers, experts and/or policy analysts. In the ideal scenario, researchers know the true values and standards and so which pvalue should be used in the construction of the CI. In practical settings, however, verifiable and/or accurate information on the true values or standards is usually absent or partial. In addition, more often than not, policy makers and stakeholders (strongly) disagree about what are proper values and principles. At best, they agree on how principles and values should more or less look like ('agreed judgments'). In the present evaluation procedure, this implies that a limited agreement on the range within which the proper $p$-value should be situated is more realistic than on a unique $p$-value. Secondly, in practice, the choice for a specific $p$-value (and, hence, for a certain aggregation procedure) could be used to manipulate the CI-scores and ranks. It is, thus, important to identify this potential source of subjectivity and gain insight on how the choice for a specific version of the generalized weighted average as aggregator impacts the countries' CI-scores and rankings. Therefore, instead of hiding this ambiguity and lack of agreement by using one particular $p$-value, it is better to recognize this ambiguity and be transparent about the impact of setting different $p$-values and hence enumerating different evaluation attitudes in the computations of country $\mathrm{Cl}$-scores and rankings. Moreover, it will be illustrated below that a study of the influence of setting different $p$-values in the CI-building also yields interesting information for policy makers and evaluators. In the next section, the impact of using different versions of the generalized weighted average aggregation operators in the construction of the HDI is explored.

\section{Human Development Index}

To illustrate the idea of using of the generalized weighted average to convey and emulate the decision maker/evaluator's attitude (following insights of Guh et al., 2008) in the construction of CIs and, thus, the role and the impact of setting different $p$-values in the formula as in (3), seven versions of the generalized weighted average HDI-scores and ranks are computed..$^{5}$ In the computations of these versions of the HDI, the functional form of the aggregator is varied (by setting different $p$-values, i.e. $p$-values equal to $-\infty,-1,0,+1,+2,+3$, and $+\infty)$. All versions of the HDI are constructed using the 'indirect' BoD-approach of Van Puyenbroeck and Rogge (2017). ${ }^{6}$ It concerns a two-step procedure in which, in a first step, importance BoD-model (Cherchye, Lovell, Moesen, \& Van Puyenbroeck, 2007; Melyn \& Moesen, 1991):

\footnotetext{
5 The decision makers/evaluators of countries' human development performances are, for instance, UNDP who is responsible for the publishing of the annual HDI or other international non-governmental organizations (e.g., International Human Development Organization, Oxford Poverty \& Human Development Initiative) who are active in the monitoring and promoting of human development.

${ }^{6}$ Note, however, that the generalized weighted average can be straightforwardly implemented as aggregator in the traditional BoD-model (i.e., the 'direct' BoDapproach):

$C I_{c}=\max _{w_{c, i}}\left(\sum_{i=1}^{m} w_{c, i}\left(y_{c, i}\right)^{p}\right)^{1 / p}$

s.t.

$\left(\sum_{i=1}^{m} w_{c, i}\left(y_{c, i}\right)^{p}\right)^{1 / p} \leq 1 \quad \forall j=1, \ldots, N$

$w_{c, i} \geq 0 \quad \forall i=1, \ldots, m$
}

$$
\max _{w_{c, i}} \sum_{i=1}^{m} w_{c, i} y_{c, i}
$$

s.t.

$\sum_{i=1}^{m} w_{c, i} y_{c, i} \leq 1 \quad \forall j=1, \ldots, N$

$w_{c, i} \geq 0 \quad \forall i=1, \ldots, m$

The objective function of (7) normally constitutes the basic linear BoD composite indicator. In the indirect BoD-approach of Van Puyenbroeck and Rogge (2017), however, the sum of BoD-weights times their associated sub-indicator values provides only an intermediate result. In particular, the indirect BoD-approach uses the BoD-derived weights $w_{c, i}$ to determine sub-indicator importance weights that are used (in the second step of the model) to construct CIs as weighted averages. More precisely, the "pie-shares" of the traditional BoD-model which designate the relative importance of each sub-indicator (i.e., $w_{c, i} y_{c, i} / \sum_{i=1}^{m} w_{c, i} y_{c, i}$ ), are used as sub-indicator importance weights $\omega_{c, i}$ in the computation of the CIs (see Cherchye and Lovell et al. (2007), Cherchye and Moesen et al. (2007) for a more detailed discussion of the pie-shares). ${ }^{7}$ More precisely, the optimal BoD-derived sub-indicator importance weights $\omega_{c, i}$ for each country are considered in the specification of the uniform set of cross-country sub-indicator importance weights (with each country's sub-indicator importance weights having a weight of $1 / N$, with $N$ being the number of countries in the sample), following the notion of cross-efficiency, as developed by Sexton, Silkman, and Hogan (1986) and Doyle and Green (1994), (see also Cook \& Zhu, 2015). In other words, in the computations below, the same set of cross-country BoD-derived importance weights is applied uniformly to all countries. One advantage of keeping the sub-indicator weights fixed is that this provides a better picture of how the choice for a specific version of the generalized (weighted) average as aggregator impacts the HDI-scores and the corresponding CI-ranks. Another advantage is that it enables complete multilateral country comparisons and rankings (the reasoning being that using country-specific optimal BoD-weights may perhaps provide useful information for that specific country itself, but may be considered unsatisfactory from a truly multilateral perspective). A particular advantage of using cross-country BoD-derived importance weights instead of any other set of fixed weights (e.g. equal weights such as in the official HDI) is that the use of each country's BoD-based optimal weights in the definition of the cross-country BoD-derived importance weight provides a pragmatic compromise in what is typically a sensitive setting (countries being evaluated relative to each other).

Whereas in the second step, Van Puyenbroeck and Rogge (2017) only consider the geometric weighted average as aggregation operator in the construction of CIs, below a broader diversity of aggregation operators as produced by the generalized weighted average, is explored. In the computations, as CIs are ultimately constructed for comparing (aggregate) relative performances of different entities (mostly countries) among each other and/or over time, in the second step, accordingly (normalized) sub-indicator values $y_{c, i}^{n}=y_{c, i} / y_{B, i}$ are used, with $y_{c, i}$ and $y_{B, i}$ the value of the evaluated country $c$ and the benchmark country $B$ on the sub-indicator $i(i=1, \ldots, m)$. In case of the HDI, Norway is used as the bench-

\footnotetext{
7 An important advantage of using pie-shares as sub-indicator importance weights in the computation of generalized weighted average CIs (second step of the indirect procedure) is the units invariance property (see e.g. Theorem 2.2 in Cooper, Seiford \& Tone, 2000), implying that $\omega_{c, i}$ is unaffected by a rescaling of the sub-indicator.
} 

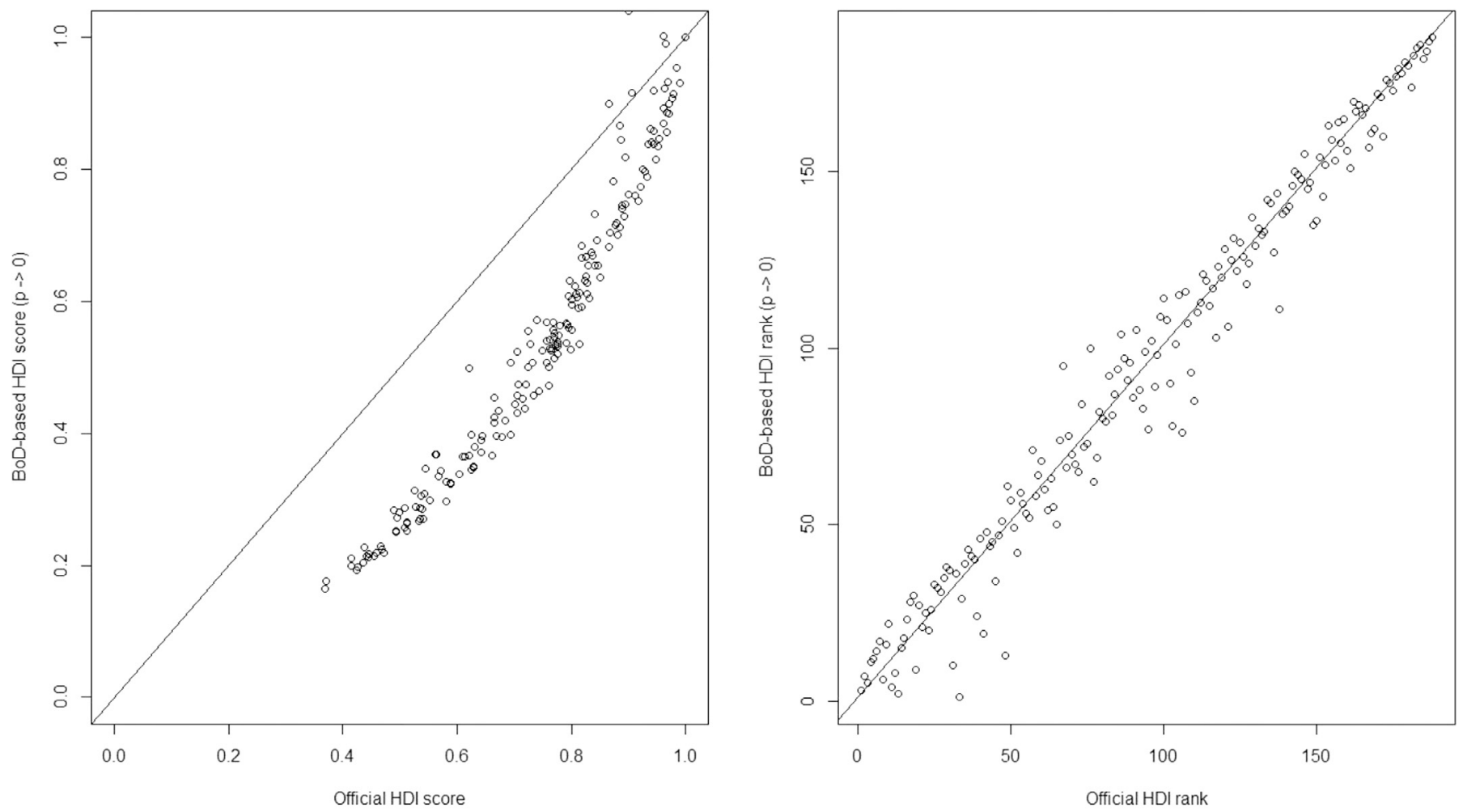

Fig. 1. Scatter plots official HDI vs geometric weighted average HDI (scores and ranks)

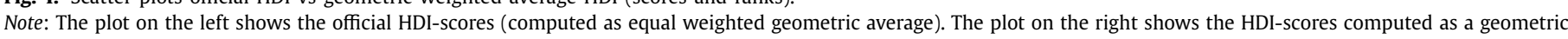

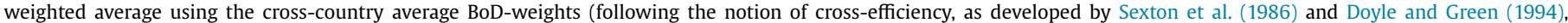
(see also Cook \& Zhu, 2015)).

mark performance standard $y_{B, i}$ given that this country is ranked highest in the official HDI-ranking. ${ }^{8}$

The plots in Fig. 1 compare the official version of the HDI scores and ranks (in essence it concerns a geometric equal weighted average of the human development sub-indicators) with the geometric BoD-weighted average HDI scores and ranks (i.e., for $\mathrm{p} \rightarrow 0$ ). The plots reveal that there is some impact of using cross-country derived BoD-weights in the computation of the HDI. In particular, the plot on the left shows that the range of the BoD-based HDI-scores is more narrow than the official equal-weighted HDI-scores. In other words, human development across countries in the sample is evaluated to be less heterogeneous when being measured using the BoD-principle in the definition of the sub-indicator importance weights as compared to equal weighting. The explanation is that, as compared to equal weighting, the BoD-derived cross-country weights enable for the 'average country' to put more (less) importance weight on human development sub-indicators with higher (lower) performance values. Stated differently, as the BoD-model used in step 1 of the indirect approach of Van Puyenbroeck and Rogge (2017) determines for each country sub-indicator importance weights such as to weigh human development sub-indicators of relative strength more heavily and human development subindicators on which the country realizes lower performance values less heavily, and given that the optimal BoD-based importance weights of all countries are considered in the specification of the cross-country importance weights, the net result is that countries are evaluated as more alike in terms of human development. In

\footnotetext{
${ }^{8}$ This is largely an arbitrary choice. Here we take it that the intuitive reading of a $\mathrm{CI}$ is fostered by using the sub-indicator values of the best performing country as a base performance measure. Other possible base performance values could be, e.g., the sample average of each sub-indicator.
}

terms of the HDI-ranking, as displayed in the plot at the right in Fig. 1, the impact is generally relatively small. Slightly less than one out of five countries (i.e., 31 of the 188 countries) have a rank change higher than 10 positions. Only few countries experience a large change in the ranking position, with Cuba $(-28)$ seeing the highest drop in the ranking and Kuwait $(+35)$ seeing the highest increase in ranking as compared to the official HDI ranking. Note that there are some countries at the top of the ranking that obtain a higher ranking under BoD-weighting as compared to equal weighting. Examples are Signapore, Hong Kong, China (SAR), Liechtenstein, Luxembourg and Qatar. In general, the countries that benefit most from applying the BoD-principle in the construction of the HDI, with a relatively high positive change in the HDI-ranking, are the ones that perform relatively strongly on the sub-indicators 'gross national income (GNI) per capita' and/or 'life expectancy at birth (years)' vis-à-vis the other countries in the sample. The reason is that the set of cross-country BoD-based importance weights specifies higher importance weights for these human development sub-indicators (i.e., 36.7\% and 25.2\%).

Using the uniform set of BoD-based cross-country weights, different versions of the HDI are computed using generalized weighted average operator as in (3) with different $p$-values. Figs. 2 and 3 offer more detailed insights into the differences in the HDI-scores and ranks that are attributable to the aggregation function used. Fig. 2 compares the geometric BoD-weighted average HDI-scores with the other versions of the generalized BoD-weighted average HDI-scores (for $p$-values equal to $-\infty,-1,+1,+2,+3$ and $+\infty)$. Fig. 3 shows the same comparisons, however, for the associated HDI-ranks. The horizontal axis displays in each plot the geometric BoD-weighted HDI, the vertical axis shows the other versions of the BoD-weighted average HDI. A general observation in the plots is that the HDI- 


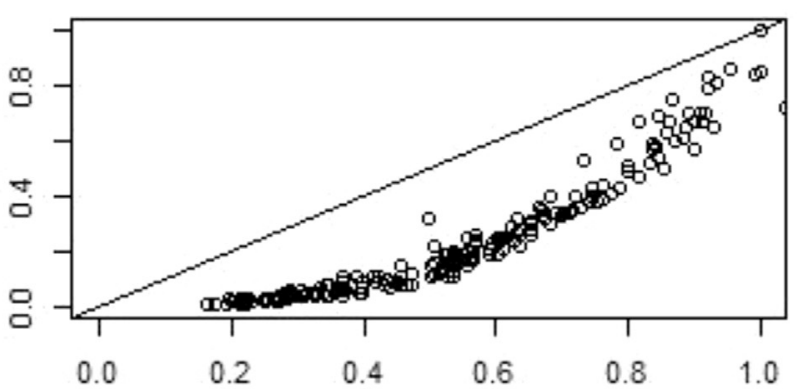

BoD-based HDI score $(p \rightarrow 0)$
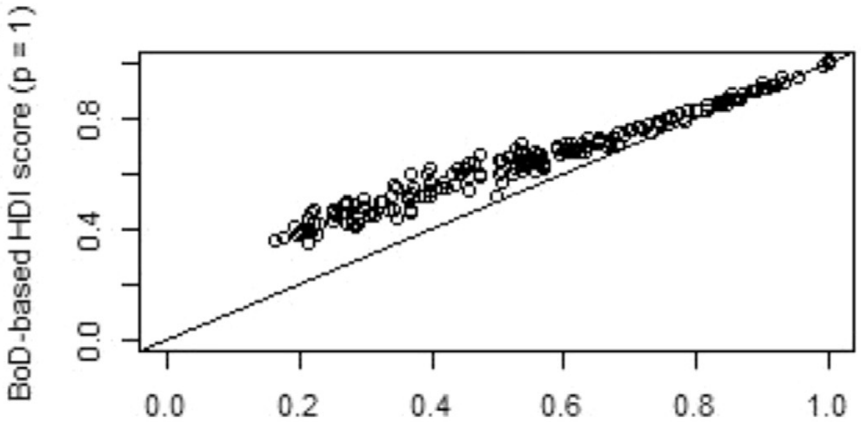

BoD-based HDI score $(\mathrm{p} \rightarrow 0)$
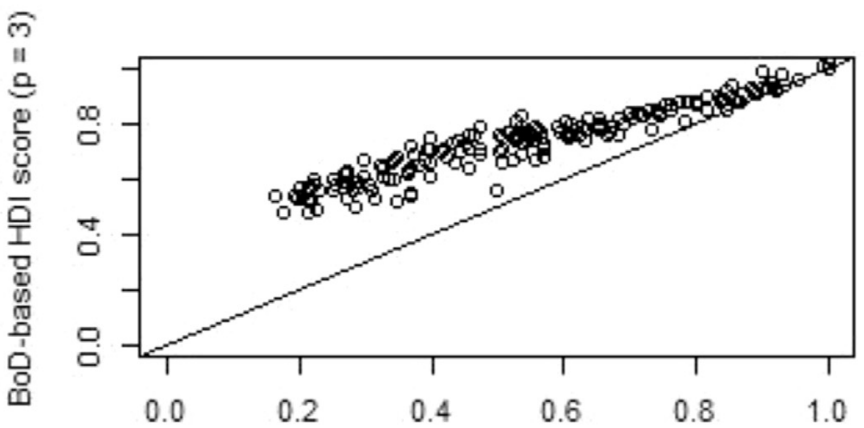

BoD-based HDI score $(p->0)$
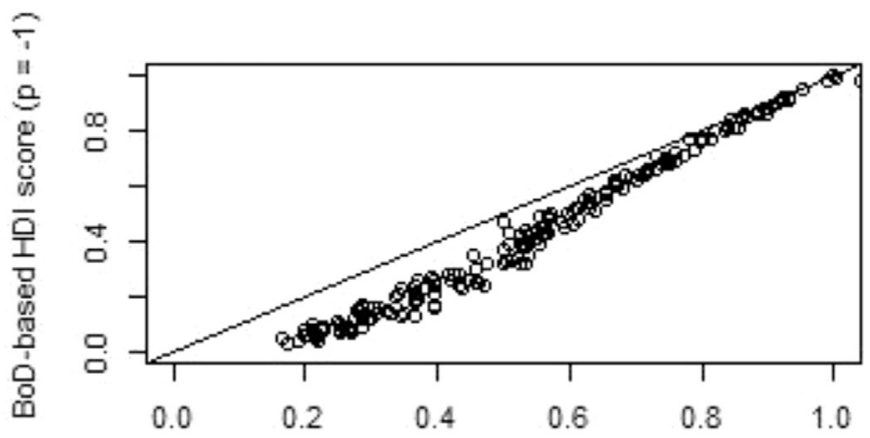

BoD-based HDI score $(p->0)$
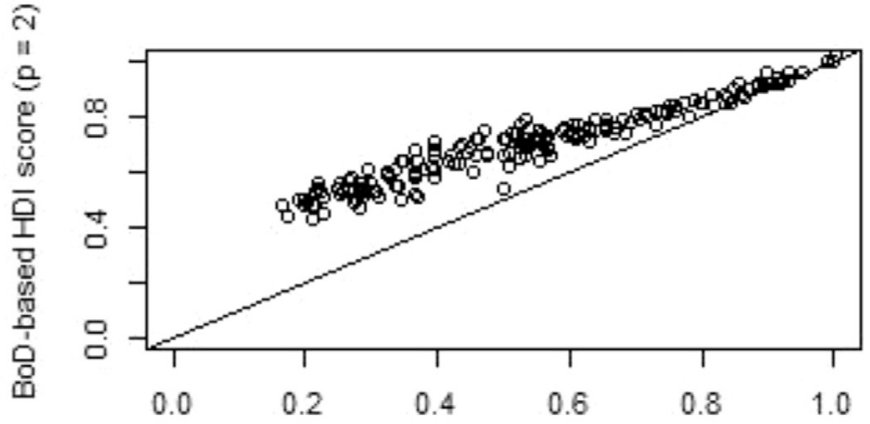

BoD-based HDI score ( $p \rightarrow 0)$
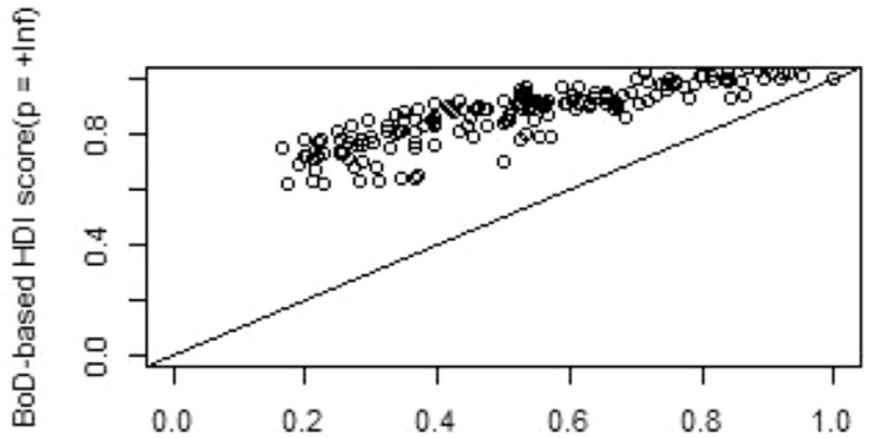

BoD-based HDI score $(p \rightarrow 0)$

Fig. 2. Scatter plots geometric weighted HDI scores vs other versions of generalized weighted average HDI scores (for p-values equal to $-\infty,-1,+1,+2,+3$ and $+\infty$ ).

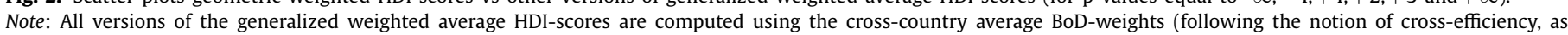
developed by Sexton et al. (1986) and Doyle and Green (1994), (see also Cook \& Zhu, 2015)).

scores are higher for higher $p$-values. In particular, we see that: $C I_{c}(p=-\infty) \leq C I_{c}(p=-2) \leq C I_{c}(p=-1) \leq C I_{c}(p=0) \leq C I_{c}(p=+1)$ $\leq C I_{c}(p=+2) \leq C I_{c}(p=+3) \leq C I_{c}(p=+\infty)$. As discussed previously, the extreme scenario's occur with $p$-values equal to respectively $\infty$ and $+\infty$. In these scenarios, the evaluated country's HDI-scores corresponds to the minimum (maximum) relative performance value of the evaluated country across the human development sub-indicators. Another general remark in the plots with the HDI-scores is that the high ranked countries are more closely situated to the 45-degree line in comparison to the countries in the middle and at the bottom of the HDI-ranking. This denotes that the top-ranked countries' HDI-scores are less influenced by the choice of the $p$-value, the reason being their strong and highly balanced performances on the human development sub-indicators.

As to the scatter plots with the HDI-ranks in Fig. 3, note that the observation of an increase in $p$-value benefiting the HDI evaluation does not hold for the HDI-ranks: higher $p$-values are not necessarily resulting in higher HDI-ranks, ceteris paribus. The reason is that an increase in the $p$-value does always result in winners and losers in terms of the HDI-rank. The winners are the countries whose HDI-score benefits relatively more from the increase in the $p$-value (causing a rank improvement). The losers are the countries whose HDI-score only benefits a little from the higher $p$ value, resulting in a lower HDI-rank. The countries winning mostly in the HDI-ranking when the $p$-value increases are countries are Cuba, Georgia, Vietnam, Nicaragua, and Albania. The countries suffering the greatest drop in the ranking as the $p$-value is higher are Equatorial Guinea, Botswana, Gabon, Trinidad and Tobago and Angola. The scatter plots of the HDI-ranks in Fig. 3 for the $p$-values equal to -1 and +1 (both plotted against the HDI-ranks for the $p$ value equal to 0 ) show that the HDI rank is rather insensitive to the choice of the $p$-values within the range $[-1,+1]$. This implies that, abstracting from any conceptual and/or theoretical reasons, in terms of the HDI-ranking the impact of computing the HDI com- 

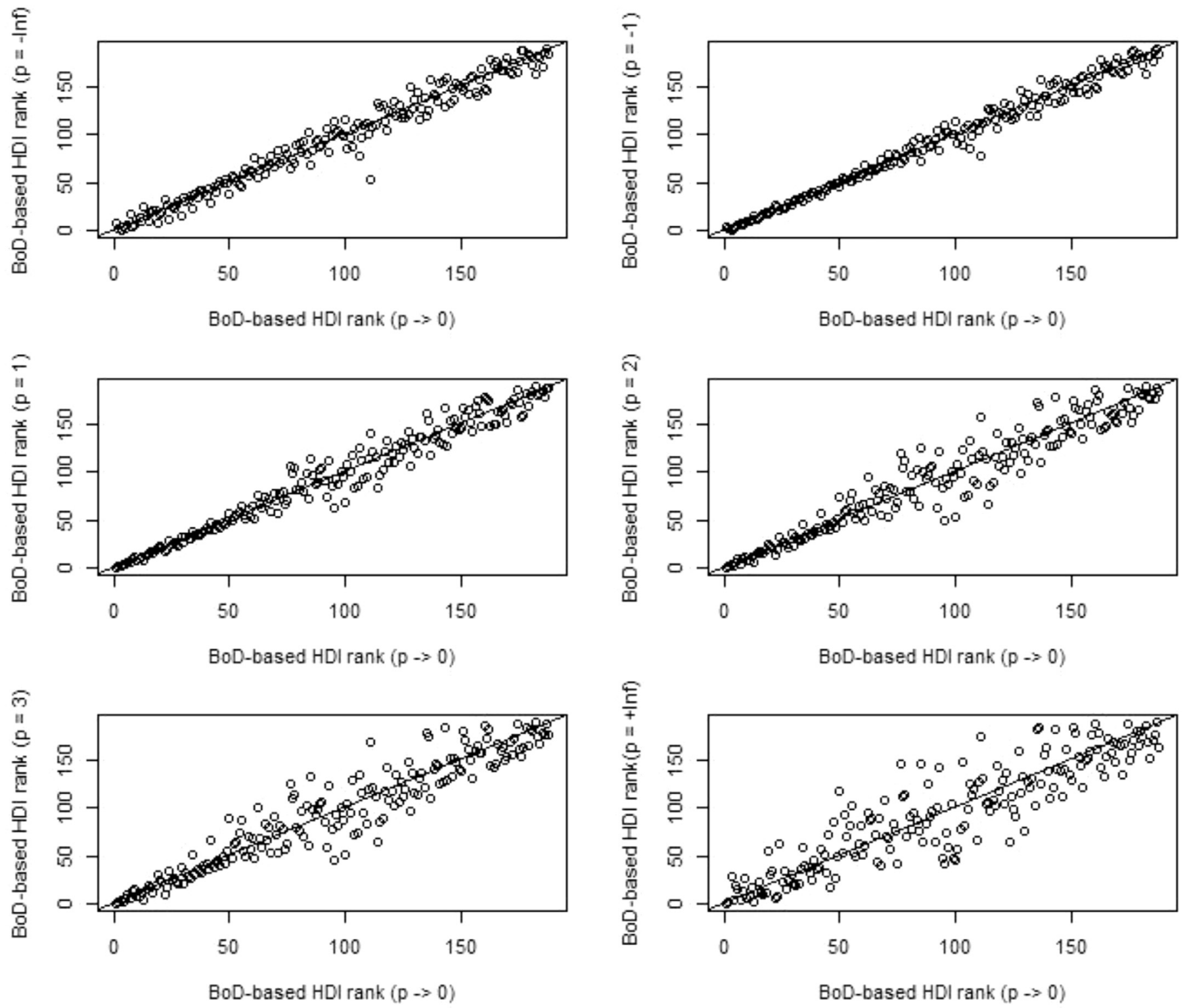

Fig. 3. Scatter plots geometric weighted HDI ranks vs other versions of generalized weighted average HDI ranks (for $\mathrm{p}$-values equal to $-\infty$, $-1,+1,+2,+3$ and $+\infty$ ).

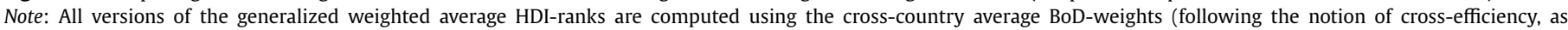
developed by Sexton et al. (1986) and Doyle and Green (1994), (see also Cook \& Zhu, 2015)).

posite indicator as a geometric, arithmetic or harmonic weighted average is relatively limited. Another observation in the plots of Fig. 3 is that countries appearing at the top or at the bottom of the ranking are fairly insensitive to the selection of a specific version of the generalized weighted average as aggregation operator. A somewhat different conclusion holds for countries in the middle of the HDI-ranking, these countries are typically most sensitive to the choice of the $p$-value. A possible explanation is that countries on the top of the ranking have characteristically highly balanced and strong performances on the human development sub-indicators and countries at the bottom have typically highly balanced yet poor performances on the set of sub-indicators, whereas countries in the middle of the ranking have more unbalanced performances on the set of human development subindicators. Stated otherwise, most of the countries in the middle of the ranking perform more heterogeneously on the human development sub-indicators vis-à-vis the countries appearing at the top and at the bottom of the HDI-ranking, with these countries do- ing relatively well on some sub-indicators but also relatively poorly on some of the other sub-indicators. Most illustrative examples of such countries are Dominica (official HDI-rank 94th), Ukraine (82th), Maldives (104th), Tonga (100th), and Vietnam (118th). Note, however, that this remark does not hold for all countries in the middle of the HDI-ranking. As can be seen in the plots, some of the middle performers are located near the 45-degree line which shows that the HDI-ranking of these countries are less sensitive to the choice of the $p$-value. Typically, these countries have an overall balanced, but mediocre performance on the set of human development sub-indicators. Jordan (80th), Peru (84th), Thailand (93th), Colombia (97th), and Paraguay (112th) are examples of such countries.

The relatively high overall correlations between the HDI-scores and ranks as computed using different versions of the generalized (weighted) average as aggregator (i.e., different $p$-values) and the cross-country average sub-indicator importance weights also shows in Table 1, with Pearson correlations coefficients for the 
Table 1

Pearson and Spearman rank correlations for the CI-scores and ranks.

\begin{tabular}{llllllll}
\hline Scores & $\mathrm{p}=-\infty$ & $\mathrm{p}=-1$ & $\mathrm{p}=0$ & $\mathrm{p}=1$ & $\mathrm{p}=2$ & $\mathrm{p}=3$ & $\mathrm{p}=+\infty$ \\
\hline $\mathrm{p}=-\infty$ & 1.0000 & & & & & & \\
$\mathrm{p}=-1$ & .7836 & 1.0000 & & & & & \\
$\mathrm{p}=0$ & .7741 & .9740 & 1.0000 & & & & \\
$\mathrm{p}=1$ & .7598 & .9545 & .9953 & 1.0000 & & & \\
$\mathrm{p}=2$ & .7507 & .9428 & .9892 & .9986 & 1.0000 & & \\
$\mathrm{p}=3$ & .7450 & .9352 & .9845 & .9966 & .9995 & 1.0000 & \\
$\mathrm{p}=+\infty$ & .7212 & .7827 & .8189 & .8290 & .8338 & .8380 & 1.0000 \\
\hline Ranks & $\mathrm{p}=-\infty$ & $\mathrm{p}=-1$ & $\mathrm{p}=0$ & $\mathrm{p}=1$ & $\mathrm{p}=2$ & $\mathrm{p}=3$ & $\mathrm{p}=+\infty$ \\
$\mathrm{p}=-\infty$ & 1.0000 & & & & & & \\
$\mathrm{p}=-1$ & .9448 & 1.0000 & & & & & \\
$\mathrm{p}=0$ & .8885 & .9850 & 1.0000 & & & & \\
$\mathrm{p}=1$ & .8682 & .9747 & .9973 & 1.0000 & & & \\
$\mathrm{p}=2$ & .8600 & .9684 & .9933 & .9985 & 1.0000 & & \\
$\mathrm{p}=3$ & .8556 & .9640 & .9900 & .9966 & .9993 & 1.0000 & \\
$\mathrm{p}=+\infty$ & .8584 & .9444 & .9642 & .9706 & .9749 & .9770 & 1.0000
\end{tabular}

HDI-scores ranging from $\mathrm{R}=0.7212$ to $\mathrm{R}=0.9995$ and Spearman rank correlations for the HDI-ranks varying between $R_{S}=0.8556$ and $R_{S}=0.9993$. The high correspondence of the HDI-scores and ranks as computed using the different versions of the generalized weighted average as aggregator is also confirmed by the Wilcoxon signed rank test, the non-parametric equivalent of the paired $t$ test (see Conover, 1980), with the series of tests indicating that the HDI-ranks of the different computed versions of the HDI are statistically significantly related. ${ }^{9}$

The finding of HDI-rankings being generally rather robust to the use of different versions of the generalized weighted average as aggregator in the computation of the HDI suggests that one can be more or less confident that the HDI rankings provide a relatively good picture of the countries' relative performances on the set of human development sub-indicators irrespective of the decision maker's evaluation attitude (i.e., the selected $p$-value). However, a high correlation between HDI-scores (rankings) resulting from different versions of the generalized weighted average as aggregator does not imply that HDI-scores and rankings are completely equivalent. ${ }^{10}$ On the contrary, a detailed study of the results shows that for all but one (i.e., Liechtenstein) of the countries in the sample the HDI-ranking depends on the specific version of the generalized weighted average used as aggregator in the $\mathrm{Cl}$-construction. As a matter of fact, that ranking differences exist straightforwardly follows from the plots in Fig. 3.

The observation that HDI-rankings as derived using the different versions of the generalized weighted average, may considerably differ for some individual countries is highlighted in the following on the basis of particular illustrative cases. Table 2 shows the top-15 of countries whose HDI-rankings are respectively most and least sensitive to the choice for a specific version of the generalized weighted average aggregator. Liechtenstein is the only country whose HDI-ranking is not sensitive to the choice of the $p$-value. The country is ranked 2nd in the HDI-ranking in all computations. For all other countries the HDI-ranking is to some extent depending on the $p$-value and, hence, on the specific version of the generalized weighted average used as aggregator in the Cl-construction.

\footnotetext{
${ }^{9}$ The assumption that the differences follow a normal distribution (as needed for the $t$-test) was not confirmed in our case. In contrast, the only assumption required for the Wilcoxon test, that the distribution of the differences is symmetric, was confirmed.

${ }^{10}$ Of course, as noted by Van den Bossche et al. (2010), "all reasonable composite scores [here, the HDI-scores computed based on different versions of the generalized weighted average as aggregator] would return the same logical ordering of the performances in the trivial case where a multi-dimensional dominance relation at the level of the performance criteria [the HDI sub-indicators] existed". But settings in which a complete ordering can be achieved in such an uncontested manner are rare, if they exist at all.
}

Unsurprisingly, the majority of the countries appearing in the top15 of countries being least sensitive to the choice of aggregation operator, appear in the top and bottom of the HDI-ranking (Singapore, Germany, Canada, the Netherlands, Denmark and France being ranked at the top and countries such as Central African Republic, Mozambique and Papua New Guinea being ranked at the bottom of the HDI-ranking). This confirms the earlier remark that for the best and worst performing countries in the HDI-ranking the impact of setting different $p$-values for the generalized weighted average aggregation operator is rather mild. The country Iran (Islamic Republic of) is somewhat an exception to this general observation with a median HDI-ranking of 70 and an average absolute rank difference of 1 across computations with different $p$-values. This suggests that Iran seems to be characterized by a rather balanced, yet, mediocre performance across the human development dimensions. This is also confirmed by the sub-indicator data, with the country ranking 62th, 46th, 100th and 73th on the four HDI sub-indicators $y_{1}$ to $y_{4}$.

The top-15 of countries with the highest differences in HDIranking across computations consists primarily of countries that appear in the middle of the HDI-ranking. In general, these countries are characterized by more or less unbalanced performances across the human development sub-indicators. Equatorial Guinea is the country in the sample of 188 countries whose HDI-ranking depends most on the specified $p$-value, with the HDI-ranking ranging between a 54th ranking and 174th ranking position across the computations. Remarkable is that Equatorial Guinea obtains its highest and lowest HDI-ranking position when being evaluated with a $p$-value equal to respectively $-\infty$ and $+\infty$ for the generalized weighted average aggregator. In fact, the ranking position of the country gradually deteriorates for increasing $p$-values. In other words, Equatorial Guinea benefits from setting lower $p$-values and, hence, a more harsh evaluation attitude in the CI-computations, as it affects the HDI-scores of most other countries more negatively than the own HDI-score. The opposite holds for increases in the $p$-values and thus a less stringent evaluation attitude in the $\mathrm{CI}$ computations. Such an attitude benefits the HDI-score of Equatorial Guinea less than the HDI-scores of the majority of the other countries, which explains for the continuous drop in HDI-ranking of Equatorial Guinea as $p$-values are set higher. Countries with HDIrankings that show similar evolutions in relation to the $p$-value are Trinidad and Tobago, Seychelles, Botswana, Turkmenistan and Gabon. There are also other countries in the top-15 of countries with the highest differences in HDI-ranking that show the opposite relation to the $p$-value. Countries such as Cuba, Georgia, and Tonga, for instance, show a decrease in the HDI-ranking as $p$-values are set lower. This suggests that the HDI-scores of these countries are more negatively affected by a stringent evaluation attitude as com- 
Table 2

Top 15 countries with HDI-ranking being most (least) sensitive to $p$-value.

\begin{tabular}{|c|c|c|c|c|c|}
\hline & Country & Median rank & & Country & Median rank \\
\hline 1. & Liechtenstein & $2(0)$ & 1. & Equatorial Guinea & $139(56)$ \\
\hline 2. & Singapore & $4(1)$ & 2. & Gabon & $113(37)$ \\
\hline 3. & Central African Republic & $187(1)$ & 3. & Botswana & $106(37)$ \\
\hline 4. & Mozambique & $180(1)$ & 4. & Cuba & $63(37)$ \\
\hline 5. & France & $25(1)$ & 5. & Georgia & $68(36)$ \\
\hline 6. & Iran (Islamic Republic of) & $70(1)$ & 6. & Tonga & $107(34)$ \\
\hline 7. & Papua New Guinea & $158(1)$ & 7. & Trinidad and Tobago & 57 (33) \\
\hline 8. & Cyprus & $37(2)$ & 8. & Angola & $161(32)$ \\
\hline 9. & Germany & $14(2)$ & 9. & Nigeria & $167(28)$ \\
\hline 10. & Uruguay & $56(2)$ & 10. & Swaziland & $154(28)$ \\
\hline 11. & Denmark & $10(2)$ & 11. & Turkmenistan & 111 (27) \\
\hline 12. & Slovakia & $40(2)$ & 12. & Iraq & $124(27)$ \\
\hline 13. & Netherlands & $12(2)$ & 13. & South Africa & $117(27)$ \\
\hline 14. & Canada & $17(2)$ & 14. & Kyrgyzstan & $116(26)$ \\
\hline 15. & Brunei Darussalam & $9(2)$ & 15. & Seychelles & $64(25)$ \\
\hline
\end{tabular}

Note: Average (absolute) rank difference between brackets.

pared to the majority of the other countries in the sample. These countries are therefore strongly discriminated against when being evaluated according to the generalized weighted average aggregator with $p$-values that approach or are equal to $-\infty$.

In sum, whereas the high correlations between the different HDI-scores and rankings computed using different $p$-values indicate that the overall HDI-ranking is on average rather robust to the use of different versions of the generalized weighted average as aggregator in the $\mathrm{Cl}$-construction, an analysis of the detailed results reveals that for some individual countries the choice for a specific $p$-value does considerably influence the HDI-score and ranking. A detailed analysis of the results shows that particularly countries with unbalanced performances on the set of human development sub-indicators are most sensitive to the $p$-value. Given the earlier remark of being transparent about the impact of using different versions of the generalized weighted average as aggregator in $\mathrm{CI}-$ building, the present findings for the HDI clearly indicate the importance of testing the robustness of the country rankings (using, e.g., uncertainty and sensitivity analysis as advocated by Saisana, Saltelli, \& Tarantola, 2005).

Before concluding this section, one final and important remark is that the present analysis sidestepped the issue of nonuniqueness of BoD-weights in the first step of the indirect procedure of Van Puyenbroeck and Rogge (2017), i.e. model (7). The possible existence of alternate sets of BoD-weights is an inherent feature of the BoD-model and of the standard DEA ("multiplier") models more generally. They pose few problems in a direct BoDapproach, insofar as the main concern there is with the resulting (and in all alternate cases maximal) value of the objective function. Instead, in the setting of the present paper, this potential issue of non-uniqueness of the BoD-weights evidently does carry over to the second step of the BoD-procedure with the set of BoD-based cross-country importance weights for the sub-indicators and hence countries' CI-values being impacted. Note, however, that the problem of non-unique BoD-weights can be overcome by using one of the different additional selection mechanisms that have been proposed in the DEA/BoD-literature (see, e.g. Cooper, Ruiz, \& Sirvent, 2007; Doyle \& Green, 1994; Liang, Wu, Cook, \& Zhu, 2008; Wang \& Chin, 2010). However, the issue here is that there is no standard selection procedure. Doyle and Green (1994) and Liang et al. (2008), for instance, proposed several selection mechanisms (e.g., benevolent and aggressive secondary goals) among the multiple optima. Others have proposed alternative mechanisms like selecting symmetric weights (Jahanshahloo, Lotfi, Jafari \& Maddahi, 2011) and rank priority (Wu, Liang, Zha \& Yang, 2009). A detailed study of the impact of using different additional selection mechanisms among the multiple optima is interesting, however, I do think that this is less relevant for the content of the present paper given that it does not influence the core idea that the choice for a specific member of the generalized weighted average can be used to convey and emulate the decision maker's attitude (following insights of Guh et al., 2008), i.e. setting more negative (positive) p-values emulating a more harsh (mild) evaluation attitude in the construction of the human development composite index. Nevertheless, a further analysis of this issue, while falling beyond the scope of the current paper, seems warranted.

\section{Topics for further research}

The integration of the generalized weighted average as aggregation operator in the BoD-framework raises several new questions and room for further research. An obvious topic for further research is the exploration of generalized weighted averages as aggregators in the intertemporal BoD-framework. ${ }^{11}$ In particular, the dynamic version of the BoD-based CIs which is inspired by the well-known Malmquist Productivity Index (MPI) of Färe, Grosskopf, Norris, and Zhang (1994), Färe, Grosskopf, Lindgren, and Roos (1994), can be straightforwardly adjusted such that it is constructed using generalized weighted average CIs.

$P C_{c}=\left[\frac{\left(\sum_{i=1}^{m} w_{c, i}^{t}\left(y_{c, i}^{t+1}\right)^{p}\right)^{1 / p}}{\left(\sum_{i=1}^{m} w_{c, i}^{t}\left(y_{c, i}^{t}\right)^{p}\right)^{1 / p}}\right]^{1 / 2}\left[\frac{\left(\sum_{i=1}^{m} w_{c, i}^{t+1}\left(y_{c, i}^{t+1}\right)^{p}\right)^{1 / p}}{\left(\sum_{i=1}^{m} w_{c, i}^{t+1}\left(y_{c, i}^{t}\right)^{p}\right)^{1 / p}}\right]^{1 / 2}$

With $P C_{C}$ the BoD-based measure of country performance change between period $t$ and $t+1$. The nominators and the denominators in (8) are equal to four different versions of the generalized weighted average $C I_{c}: C I_{c}$ calculated by observation data of period $t+1$ and importance weights at period $t, C_{c}$ computed using both observation data and importance weights of period $t, \mathrm{CI}_{C}$ calculated using both observation and importance weights of period $t+1$, and $C I_{c}$ obtained using observation data at period $t$ and importance weights of period $t+1$. Similar to its static counterpart (as discussed in the present paper), of particular interest is the parameter $p$. Setting a high (low) $p$-value implies that the evaluation

\footnotetext{
11 The dynamic BoD-based performance change measure with arithmetic weighted average CIs has been used in several past studies. Examples of studies include Cherchye, Lovell, Moesen and Van Puyenbroeck (2007) for the Internal Market Index in the EU, Kortelainen (2008) and Picazo-Tadeo, Castillo-Giménez and BeltránEsteve (2014) for measuring environmental performance in the European Union, and Lefebvre, Coelli and Pestieau (2010) for assessing social protection performance in the European Union.
} 
of performance change is largely determined by the performance change realized by the evaluated country on the sub-indicators on which it performs more strongly (poorly) as compared to the other countries. Setting an intermediate $p$-value means balancing to a certain degree performance change realized on sub-indicators on which the assessed country performs relatively strongly with performance change realized on sub-indicators on which it performs relatively weakly vis-à-vis the other countries, the degree depending on the actual $p$-value. The interpretation of the results of the generalized (weighted) average $P C_{c}$ is analogous to the traditional arithmetic weighted average $P C_{c}: P C_{c}>1\left(P C_{c}<1\right)$ indicating that the evaluated country generally experienced progress (regress) in its performance vis-à-vis the other countries. A $P C_{c}$-value of one indicates a status quo in the country's relative performance between $t$ and $t+1$. Akin to the original MPI, the BoD-based generalized weighted average $P C_{c}$ can be expressed as the product of a catching-up $\left(C U_{C}\right)$ and an environmental change $\left(E C_{c}\right)$ component, with the interpretation both components remaining largely unaltered by the implementation of the generalized weighted averages. The $C U_{c}$-component measures the extent to which changes in country performance are effectively due to the country's idiosyncratic improvement, with values larger (smaller) than one indicating that the assessed country got closer (fell back) to the benchmark. The $E C_{c}$-component estimates how the policy environment has changed between $t$ and $t+1\left(E C_{c}>1\right.$ : favorably, $E C_{c}<1$ : unfavorably, or $E C_{c}=1$ : status quo) by looking at how the performances of the benchmark countries changed between $t$ and $t+1$.

Another topic for further research is the exploration of the family of generalized weighted averages in the aggregation of individual country CIs into a group CI. In fact, in another recent contribution (Rogge, 2018), it was already proposed to consider generalized weighted averages in the setting of constructing group CIs. Formally,

$C I_{G}=\left(\sum_{j=1}^{N} s_{j}\left(C I_{j}\right)^{p}\right)^{1 / p}$

With $s_{j}$ country shares for the $N$ countries $(j=1, \ldots, N)$ in the group (defined using an approach similar to Färe \& Zelenyuk, 2003). Most of the remarks made in the present paper carry over to this group Cl-setting. More in particular, by varying the parameter $p$, different versions of the generalized (weighted) average can be used as aggregation operator in the construction of the aggregate $\mathrm{CI}_{G}$. Again, one could argue that the specification of the $p$-value is a modeling option that can be used to convey and emulate the decision maker's attitude, with lower (higher) $p$ values corresponding to the implementation of a higher penalty (reward) for relatively poor (strong) performance(s) of one or more of the member countries in the determination of $C I_{G}$. The two extreme cases correspond to the $p$-values of $-\infty$ and $+\infty$. For $p=-\infty$, the aggregator $C I_{G}=\min \left\{C I_{1}, \ldots, C I_{N}\right\}$, implying that the group $C I_{G}$ corresponds to the minimum $C I_{j}$-value of the constituent countries. The other extreme case is for $p=+\infty: C I_{G}=$ $\max \left\{C I_{1}, \ldots, C I_{N}\right\}$. In this case, the aggregate $C I_{G}$ equals the maximum $C I_{j}$-value across the member countries.

Other topics in the literature which offer plenty of scope for further research for handling the generalized weighted average as aggregator in BoD-based CIs, are the uncertainty and sensitivity analysis of CIs as constructed with different versions of the generalized weighted average as aggregator (e.g. Cherchye et al., 2008; Saisana et al., 2005) and the statistical inference of CIs as computed with different $p$-values for the generalized weighted average (see, Simar \& Wilson, 2000, 2006).

\section{Conclusions}

This paper takes the exploration for proper aggregation procedures in CI-building one step further by considering other members of the family of generalized weighted average functions as aggregators in a BoD-framework. More in particular, it was argued that a $\mathrm{Cl}$-construction method that combines generalized (weighted) averages as aggregation operators in combination with "benefit of the doubt"-weighting has more potential to evaluate policy performance in real decision making situations that are usually characterized by incomplete and/or imprecise information on the true importance weights of the sub-indicators comprising the $\mathrm{CI}$ as well as the evaluation attitude of the decision maker(s). As to the latter, it is argued that the flexibility in choosing a specific member of the generalized (weighted) averages as aggregator in the construction of CIs can be used to reflect the evaluation attitude of the decision maker.

To illustrate the use of the generalized weighted average as aggregator (and, thus, the role and the impact of setting different $p$-values) in the construction of CIs, versions of HDI were computed for different $p$-values using cross-country average BoD-based sub-indicator importance weights (following the notion of crossefficiency). Overall results show high correlations between the different HDI-scores and rankings computed using different $p$-values. This suggests that the overall HDI-ranking is on average rather robust to the use of different versions of the generalized weighted average as aggregator in the $\mathrm{CI}$-construction. On the other hand, results show that for some individual countries the choice for a specific version of the generalized weighted average as aggregator considerably impacts the resulting HDI-rankings. A key finding was that the majority of the countries appearing in the top-15 of countries being least sensitive to the choice of aggregation operator appear in the top and bottom of the HDI-ranking. Countries with the highest differences in HDI-ranking across computations with different versions of the generalized weighted average as aggregator (i.e., $p$-value) appear primarily in the middle of the HDI-ranking. In general, these countries are characterized by more or less unbalanced performances across the human development sub-indicators.

The integration of the generalized weighted average as aggregation operator in the BoD-framework raises several new questions and room for further research. Four interesting topics for future research were discussed: the exploration of generalized weighted averages as aggregators in the intertemporal BoD-framework, a study of the family of generalized weighted averages in the aggregation of individual country $\mathrm{CI}$ into a group $\mathrm{Cl}$, the uncertainty and sensitivity analysis of CIs as constructed with different versions of the generalized weighted average as aggregator, and the statistical inference of CIs as computed with different $p$-values for the generalized weighted average.

\section{Acknowledgments}

This paper is an offshoot of the Impulsproject IMP/14/011 of the KU Leuven (Belgium).

\section{Appendix}

Proof 1. The generalized weighted average as in formula (3) with the p-value approaching $+\infty(-\infty)$ corresponds to respectively the maximum (minimum) value across sub-indicators. 
Proof of $\lim _{\boldsymbol{p} \rightarrow+\infty} \boldsymbol{C I}_{\boldsymbol{c}}=\max _{\boldsymbol{i}}\left(\boldsymbol{y}_{\boldsymbol{c}, \boldsymbol{i}}^{\boldsymbol{n}}\right)$. Assume that $y_{c, 1}^{n} \geq y_{c, 2}^{n} \geq \ldots \geq$ $y_{c, m}^{n}$. Then,

$$
\begin{aligned}
\lim _{p \rightarrow+\infty} C I_{c} & =\lim _{p \rightarrow+\infty}\left(\sum_{i=1}^{m} \omega_{c, i}\left(y_{c, i}^{n}\right)^{p}\right)^{1 / p} \\
& =y_{c, 1}^{n} \lim _{p \rightarrow+\infty}\left(\sum_{i=1}^{m} \omega_{c, i}\left(\frac{y_{c, i}^{n}}{y_{c, 1}^{n}}\right)^{p}\right)^{1 / p}=y_{c, 1}^{n}
\end{aligned}
$$

Proof of $\lim _{\boldsymbol{p} \rightarrow-\infty} \boldsymbol{C I _ { \boldsymbol { c } }}=\min _{\boldsymbol{i}} \boldsymbol{y}_{\boldsymbol{c}, \boldsymbol{i}}^{\mathbf{n}}$. Assume that $y_{c, 1}^{n} \geq y_{c, 2}^{n} \geq \ldots \geq y_{c, m}^{n}$. Then,

$$
\begin{aligned}
\lim _{p \rightarrow-\infty} C I_{c} & =\lim _{p \rightarrow-\infty}\left(\sum_{i=1}^{m} \omega_{c, i}\left(y_{c, i}^{n}\right)^{p}\right)^{1 / p} \\
& =y_{c, m}^{n} \lim _{p \rightarrow-\infty}\left(\sum_{i=1}^{m} \omega_{c, i}\left(\frac{y_{c, i}^{n}}{y_{c, m}^{n}}\right)^{p}\right)^{1 / p}=y_{c, m}^{n}
\end{aligned}
$$

Proof 2. The generalized weighted average as in formula (3) with the p-value approaching 0 corresponds to the geometric weighted average.

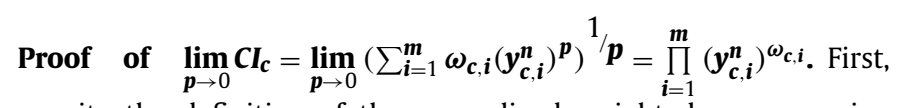
rewrite the definition of the generalized weighted average using the exponential function

$$
\begin{aligned}
C I_{c} & =\exp \left(\ln \left[\left(\sum_{i=1}^{m} \omega_{c, i}\left(y_{c, i}^{n}\right)^{p}\right)^{1 / p}\right]\right) \\
& =\exp \left(\frac{\ln \left(\sum_{i=1}^{m} \omega_{c, i}\left(y_{c, i}^{n}\right)^{p}\right)}{p}\right)
\end{aligned}
$$

In the limit $\mathrm{p} \rightarrow 0$, L'Hôpital's rule can be applied to the argument of the exponential function. In particular, differentiating both the numerator and denominator with respect to the p-parameter, yields:

$$
\begin{aligned}
\lim _{p \rightarrow 0} \frac{\ln \left(\sum_{i=1}^{m} \omega_{c, i}\left(y_{c, i}^{n}\right)^{p}\right)}{p} & =\lim _{p \rightarrow 0} \frac{\frac{\sum_{i=1}^{m} \omega_{c, i}\left(y_{c, i}^{n}\right)^{p} \ln \left(y_{c, i}^{n}\right)}{\sum_{i=1}^{m} \omega_{c, i}\left(y_{c, i}^{n}\right)^{p}}}{1} \\
& =\lim _{p \rightarrow 0} \frac{\sum_{i=1}^{m} \omega_{c, i}\left(y_{c, i}^{n}\right)^{p} \ln \left(y_{c, i}^{n}\right)}{\sum_{i=1}^{m} \omega_{c, i}\left(y_{c, i}^{n}\right)^{p}}
\end{aligned}
$$

As the importance weights sum to one, $\sum_{i=1}^{m} \omega_{c, i}=1$, the formula can be rewritten as:

$\sum_{i=1}^{m} \omega_{c, i} \ln \left(y_{c, i}^{n}\right)=\ln \left(\prod_{i=1}^{m}\left(y_{c, i}^{n}\right)^{\omega_{c, i}}\right)$

By taking the exponential we obtain $\mathrm{CI}_{c}$ :

$\lim _{p \rightarrow 0} C I_{c}=\exp \left(\ln \left(\prod_{i=1}^{m}\left(y_{c, i}^{n}\right)^{\omega_{c, i}}\right)\right)=\prod_{i=1}^{m}\left(y_{c, i}^{n}\right)^{\omega_{c, i}}$

This concludes the proof.

\section{References}

Amado, C. A., São José, J. M., \& Santos, S. P. (2016). Measuring active ageing: A data envelopment analysis approach. European Journal of Operational Research, 255(1), 207-223.

Anderson, G., Crawford, I., \& Leicester, A. (2011). Welfare rankings from multivariate data, a nonparametric approach. Journal of Public Economics, 95, 247-252.
Blancard, S., \& Hoarau, J.-F. (2013). A new sustainable human development indicator for small island developing states: A reappraisal from data envelopment analysis. Economic Modelling. 30, 623-635.

Blancas, F. J., Contreras, I., \& Ramírez-Hurtado, J. M. (2013). Constructing a composite indicator with multiplicative aggregation under the objective of ranking alternatives. Journal of the Operational Research Society, 64(5), 668-678.

Booysen, F. (2002). An overview and evaluation of composite indices of development. Social Indicators Research, 59(2), 115-151.

Chakravarty, S. R. (2003). A generalized human development index. Review of Development Economics, 7(1), 99-114.

Charnes, A., Cooper, W. W., \& Rhodes, E. (1978). Measuring the efficiency of decision making units. European Journal of Operational Research, 2, 429-444.

Cherchye, L., Lovell, C. K., Moesen, W., \& Van Puyenbroeck, T. (2007). One market, one number? A composite indicator assessment of EU internal market dynamics. European Economic Review, 51(3), 749-779.

Cherchye, L., Moesen, W., Rogge, N., \& Van Puyenbroeck, T. (2007). An introduction to 'benefit of the doubt' composite indicators. Social Indicators Research, 82, 111-145.

Cherchye, L., Moesen, W., Rogge, N., Van Puyenbroeck, T., Saisana, M., \& Saltelli, A. (2008). Creating composite indicators with DEA and robustness analysis: The case of the technology achievement index. Journal of the Operational Research Society, 59, 239-251.

Chowdhury, S., \& Squire, L. (2006). Setting weights for aggregate indices: An application to the commitment to development index and human development index. Journal of Development Studies, 42(5), 761-771.

Conover, W. J. (1980). Practical nonparametric statistics. New York: John Wiley.

Cook, W. D., \& Zhu, J. (2015). DEA cross efficiency. Data envelopment analysis (pp. 23-43). US: Springer.

Cooper, W. W., Ruiz, J. L., \& Sirvent, I. (2007). Choosing weights from alternative optimal solutions of dual multiplier models in DEA. European Journal of Operational Research, 180, 443-458.

Cooper, W. W., Seiford, L. S., \& Tone, K. (2000). DEA: A comprehensive text with models. Applications, references and DEA-solver software. London: Kluwer Academic Publishes.

Decancq, K., \& Lugo, M. A. (2013). Weights in multidimensional indices of wellbeing: An overview. Econometric Reviews, 32(1), 7-34.

Despotis, D. K. (2005a). A reassessment of the human development index via data envelopment analysis. Journal of the Operational Research Society, 56(8), 969-980.

Despotis, D. K. (2005b). Measuring human development via data envelopment analysis: The case of Asia and the Pacific. Omega, 33, 385-390.

Despotis, D. K., Stamati, L. V., \& Smirlis, Y. G. (2009). Data envelopment analysis with virtual inputs and outputs. European Journal of Operational Research, 202, 604-613.

Doyle, J., \& Green, R. (1994). Efficiency and cross-efficiency in DEA: Derivations, meanings and uses. Journal of the Operational Research Society, 45(5), 567-578.

Ebert, U., \& Welsch, H. (2004). Meaningful environmental indices: A social choice approach. Journal of Environmental Economics and Management, 47(2), 270-283.

Färe, R., Grosskopf, S., Norris, M., \& Zhang, Z. (1994). Productivity growth, technical progress, and efficiency change in industrialized countries. The American Economic Review, 84(1), 66-83.

Färe, R., Grosskopf, S., Lindgren, B., \& Roos, P. (1994). Productivity developments in Swedish hospitals: a malmquist output index approach. In A. Charnes, W. W. Cooper, A. Y. Levin, \& L. M. Seiford (Eds.), Data envelopment analysis: Theory, methodology and applications. Boston: Kluwer Academic Publishers.

Färe, R., \& Zelenyuk, V. (2003). On aggregate Farrell efficiencies. European Journal of Operational Research, 146(3), 615-620.

Guh, Y. Y., Po, R. W., \& Lee, E. S. (2008). The fuzzy weighted average within a generalized means function. Computers \& Mathematics with Applications, 55(12), 2699-2706.

Jahanshahloo, G. R., Lotfi, F. H., Jafari, Y., \& Maddahi, R. (2011). Selecting symmetric weights as a secondary goal in DEA cross-efficiency evaluation. Applied Mathematical Modelling, 35(1), 544-549.

Kortelainen, M. (2008). Dynamic environmental performance analysis: A Malmquist index approach. Ecological Economics, 64(4), 701-715.

Lefebvre, M., Coelli, T., \& Pestieau, P. (2010). On the convergence of social protection performance in the European Union. CESifo Economic Studies, 56(2), 300-322.

Liang, L., Wu, J., Cook, W. D., \& Zhu, J. (2008). Alternative secondary goals in DEA cross-efficiency evaluation. International Journal of Production Economics, 113(2), 1025-1030.

Mahlberg, B., \& Obersteiner, M. (2001). Remeasuring the HDI by data envelopment analysis. Interim Report IR-01-069. IIASA, Laxenburg (Austria).

Mariano, E. B., Sobreiro, V. A., \& do Nascimento Rebelatto, D. A. (2015). Human development and data envelopment analysis: A structured literature review. Omega, 54, 33-49.

Melyn, W., \& Moesen, W. (1991). Towards a synthetic indicator of macroeconomic performance: Unequal weighting when limited information is available. Public economics research paper 17. CES KU Leuven, Leuven.

Nardo, M., Saisana, M., Saltelli, A., Tarantola, S., Hoffman, A., \& Giovannini, E. (2008), Handbook on constructing composite indicators: Methodology and user guide. OECD \& European Commission, Joint Research Centre, OECD publication Code $302008251 \mathrm{E} 1$

Permanyer, I. (2012). Uncertainty and robustness in composite indices rankings. $O x$ ford Economic Papers, 64(1), 57-79.

Picazo-Tadeo, A. J., Castillo-Giménez, J., \& Beltrán-Esteve, M. (2014). An intertemporal approach to measuring environmental performance with directional dis- 
ID: BOR

[m5G;December 11, 2017;21:50]

12

N. Rage/ European Journal of Operational Research 000 (2017) 1-12

tance functions: Greenhouse gas emissions in the European Union. Ecological Economics, 100, 173-182.

Ravallion, M. (2012). Troubling tradeoffs in the human development index. Journal of Development Economics, 99(2), 201-209.

Rage, N. (2012). Undesirable specialization in the construction of composite policy indicators: The environmental performance index. Ecological Indicators, 23, 143-154.

Rage, N. (2018). On aggregating benefit of the doubt composite indicators. European Journal of Operational Research, 264(1), 364-369.

Sugar, A. D., \& Najam, A. (1998). The human development index: A critical review. Ecological Economics, 25(3), 249-264.

Saisana, M., Saltelli, A., \& Tarantola, S. (2005). Uncertainty and sensitivity analysis techniques as tools for the quality assessment of composite indicators. Journal of the Royal Statistical Society: Series A (Statistics in Society), 168(2), 307-323.

Sexton, T. R., Silkman, R. H., \& Hogan, A. J. (1986). Data envelopment analysis: ritique and extensions. In R. H. Silkman (Ed.), Measuring efficiency: An assessment of data envelopment analysis (pp. 73-105). San Francisco, CA: Jossey-Bass.

Simar, L., \& Wilson, P. W. (2000). Statistical inference in nonparametric frontier models: The state of the art. Journal of Productivity Analysis, 13, 49-78.

Simar, L., \& Wilson, P. W. (2006). Statistical inference in nonparametric frontier models: recent developments and perspectives. In H. Fried, C. A. Knox Lovell, \& S. Schmidt (Eds.), The measurement of productive efficiency. Oxford University Press.

Tofallis, C. (2013). An automatic-democratic approach to weight setting for the new human development index. Journal of Population Economics, 26(4), 1325-1345.
UNDP. (2010). Human development report: The real wealth of nations. New York: United Nations Development Programme.

Van den Bossche, F., Rage, N., Devooght, K., \& Van Puyenbroeck, T. (2010). Robust corporate social responsibility investment screening. Ecological Economics, 69(5), 1159-1169.

Van Puyenbroeck, T., \& Rage, N. (2017). Geometric mean quantity index numbers with benefit-of-the-doubt weights. European Journal of Operational Research, 256(3), 1004-1014.

Wang, Y. M., \& Chin, K. S. (2010). Some alternative models for DEA cross-efficiency evaluation. International Journal of Production Economics, 128(1), 332-338.

Wu, J., kiang, L., Zha, Y., \& Yang, F. (2009). Determination of cross-efficiency under the principle of rank priority in cross-evaluation. Expert Systems with Applicaions, 36(3), 4826-4829.

Canella, A., Camanho, A. S., \& Dias, T. G. (2015). Undesirable outputs and weighting schemes in composite indicators based on data envelopment analysis. European Journal of Operational Research, 245(2), 517-530.

Chou, P., Ans, B. W., \& Doh, K. L. (2007). A mathematical programming approach to constructing composite indicators. Ecological Economics, 62(2), 291-297.

Chou, P., Ans, B. W., \& Chou, D. Q. (2010). Weighting and aggregation in composide indicator construction: A multiplicative approach. Social Indicators Research, 96(1), 169-181.

Chou, P., Fan, L. W., \& Chou, D. Q. (2010). Data aggregation in constructing composite indicators: A perspective of information loss. Expert Systems with Applications, $37(1), 360-365$.

Please cite this article as: N. Rogge, Composite indicators as generalized benefit-of-the-doubt weighted averages, European Journal of

Operational Research (2017), https://doi.org/10.1016/j.ejor.2017.11.048 